\title{
A Lei em Tela e a Tela da Lei: 0 Direito e os Reality Shows*
}

\author{
Vicente Riccio
}

o presente artigo pretendo discutir, sob o enfoque da socio-
logia do direito, como concepções populares de justiça folk knowledge - são tematizadas no quadro de reality shows. Busco verificar como essas concepções exteriores ao mundo do direito oficial se manifestam em programas de variedades, levando-se em conta o contexto social em que está inserida a apresentação dos temas.

Os estudos sobre a judicialização das relações sociais, quando se debruçam sobre a manifestação desse fenômeno na mídia, normalmente, centram seu enfoque no princípio de que tais programas apresentam visões distorcidas sobre justiça baseadas no senso comum que permeia as relações sociais. Esses estudos funcionariam, também, como um fórum informal ao qual o cidadão recorreria na tentativa de suprir as dificuldades de acesso ao direito oficial.

Neste artigo, parto da hipótese de que essas análises, embora corretas em diversas circunstâncias, não são as únicas plausíveis. Os reality

\footnotetext{
*Agradeço a Luiz Werneck Vianna (IUPERJ), Isaac Joseph (Université Paris X) e Sabine Chalvon-Demersay (École des Hautes Études en Sciences Sociales), e também ao parecerista anônimo de Dados que deu sugestões fundamentais para a publicação deste artigo.

DADOS - Revista de Ciências Sociais, Rio de Janeiro, Vol. 44, no 4, 2001, pp. 773 a 805.
} 


\section{Vicente Riccio}

shows, na verdade, seriam espaços de exposição de profundos e permanentes conflitos entre o direito oficial e as concepções populares de justiça. A idéia não é julgar esse conflito — se positivo ou negativo —, mas analisá-lo para perceber como concepções populares sobre o justo se manifestam em programas de variedades e que tipo de contexto social trazem à tona.

Tenciono captar nas manifestações folk o aspecto subjetivo do direito, uma vez que o conceito de justiça contempla múltiplas interpretações e é tema constante na mídia, seja em reportagens policiais, denúncias jornalísticas, filmes ou em outro formato de programa. Ressalto, aqui, que o choque de lógicas entre o mundo do direito e o da mídia se deve às diferentes características de cada um: o primeiro mostra-se formal e pautado por regras previamente definidas. $\mathrm{O}$ segundo tem como marcas a instantaneidade, o movimento e a ausência de formalidades. Ambos discutem a socialização de valores e símbolos comuns aos indivíduos, participando da formação do consenso social.

Reconhecer que a lei comporta elementos subjetivos significa dizer que sua eficácia e valores, seus resultados práticos e sua capacidade de organizar a sociedade são permanentemente avaliados pelos indivíduos. Nos reality shows é explicitado esse julgamento popular do papel e da eficácia da lei, o que abre espaço para a avaliação das noções de justiça concebidas externamente à lógica dos operadores do direito.

Vale observar que a pluralidade de conceitos sobre o justo assume diferentes formas discursivas, em função da diversidade dos tipos de mídia e de suas linguagens específicas. A estrutura de comunicação do rádio, por exemplo, exige que uma matéria sobre uma determinada máfia de fiscais seja tratada de forma totalmente diversa da adotada por um jornal especializado em economia. Tal constatação suscita algumas perguntas: é possível analisar, a partir dos mesmos critérios, a presença do jurídico em diferentes tipos de mídia? Pode-se construir uma teoria geral para analisar a relação entre o direito e a mídia?

O tipo de discurso empregado, bem como o contexto social a partir do qual o legal e o justo são tematizados, leva ao questionamento da propriedade de se construir uma teoria generalista para estudar a presença do direito na mídia. Tal questionamento mostra-se importante na medida em que os atuais estudos tendem a uma concepção una so- 
bre o tema, estimando haver uma invasão de mão única da mídia sobre o aparato judicial.

Por todas essas razões, as seguintes hipóteses serão levantadas neste artigo: não é apropriado construir uma teoria geral sobre a relação entre direito e mídia; as concepções folk presentes na mídia, ao discutir o justo, podem oferecer subsídios para a compreensão do contexto social de judicialização das relações sociais. As concepções folk podem ser vistas como partícipes desse processo.

\section{A JUDICIALIZAÇÃO DA SOCIEDADE}

A presença do direito nas sociedades contemporâneas tem crescido consideravelmente. Hoje, abrange desde a atividade política até as relações privadas, passando por questões éticas e sociais, como o direito da ciência de manipular e recriar a vida. Como afirma Commaille, a judicialização das relações sociais é constatada no domínio das atividades econômicas e das relações de trabalho desde os anos 70: "Esta se observa, mais largamente, naquelas relações entre o cidadão e o Estado, ou, ainda, no domínio da gestão das relações entre os indivíduos no seio de sua esfera privada" (2000:242).

No mundo contemporâneo, diversos temas da política, da economia, do comportamento e da moral são incorporados pelo Judiciário, fazendo com que o direito se torne um recurso cada vez mais utilizado pelos atores sociais. A relação mídia versus lei é marcada pela tensão. Se, por um lado, ela procura fazer valer o seu papel de "cão-de-guarda" (whatchdog) da democracia, por outro, o mundo do direito insurge-se contra a usurpação do seu espaço:

"A comunicação mediática substitui o funcionamento da democracia. O grande espaço público mediático devora os 'espaços públicos restritos', que asseguram o simples exercício da democracia. A televisão torna-se a instituição que absorve todas as outras, em particular a justiça, dada a sua necessidade de dirigir, controlar, julgar e invadir tudo" (Salas, 1998:151) $)^{1}$.

Esse entendimento, presente tanto no conjunto da obra de Salas quanto em Garapon, é acompanhado da indicação de que há uma invasão excessiva do direito nos processos sociais. Questões de sociedade, cada vez mais, passam a se utilizar do recurso jurídico para expressão das suas demandas. 


\section{Vicente Riccio}

Tal fenômeno já havia sido identificado por Friedman em Total Justice (1985), no qual o autor afirma existir uma explosão do direito (law explosion), materializada no excesso de advogados e em uma judicialização cada vez maior da sociedade. Essa tendência poderia ser constatada, ainda, no surgimento de novas áreas de intervenção do direito, com a conseqüente ampliação das possibilidades de estabelecimento de litígios, e nos diversos tipos de ação existentes, como as movidas contra o governo. O argumento de Friedman centra-se na idéia de que certas mudanças na sociedade moderna provocaram modificações na cultura jurídica. Conceituadas por ele como claim consciousness (consciência de reclamação) ou law explosion, tais mudanças caracterizariam o que o autor chama de total justice (Sanders, 1987).

Esse processo, todavia, comporta duas visões distintas, ambas com avaliações desfavoráveis à mídia no que diz respeito à sua relação com o universo jurídico. A primeira observa a explosão do direito como um fenômeno negativo, em que a ampliação da influência do Estado, e, no caso, do Judiciário, leva à supremacia da burocracia sobre os indivíduos. O papel do Judiciário substituiria o papel do representante e "a criação do direito, ao invés de resultar de uma democracia de cidadãos ativos, tornar-se-ia uma construção metafísica de clérigos depositários da idéia do 'justo', em uma usurpação da soberania popular" (Werneck Vianna et alii, 1999:257).

Esse tipo de interpretação, deslocado para a análise da questão mídia/direito, aponta para a usurpação da cultura jurídica democrática pelos "clérigos" da mídia. Se "nada na cultura jurídica continental predisporia o juiz a jogar um papel político" (Salas, 1998:17), tampouco a mídia estaria legitimada a agir e a controlar o Estado. Quando, "ávidos por 'informações bombásticas', os meios de comunicação tornam-se inimigos da democracia, da qual eles subvertem o tempo e o ritmo", eles invadem o espaço simbólico do Estado (idem:156). A análise indica que o ativismo judicial e a presença do direito nas questões de sociedade resultam em uma reação à cultura jurídica da democracia representativa, em decorrência da própria crise por esta enfrentada. Essa reação contra a "invasão" é típica da razão republicana francesa, em que o direito centrado no Estado encarna a vontade democrática.

Já na avaliação positiva sobre essa interferência do direito, sua incorporação à vida cotidiana estaria ligada à práxis da vida social. Esse é o mundo em que o direito está próximo do self-government. Nesse caso, 
o Judiciário não é neutro, mas tem forte interação com a sociedade (Werneck Vianna et alii, 1999:258).

A presença do direito na vida social não é desvinculada do cultural ou do simbólico em uma dada sociedade. Nesse aspecto simbólico do direito, a mídia desempenha papel fundamental, aparecendo, mais uma vez, na avaliação de alguns autores, como usurpadora do papel do Judiciário. Garapon, por exemplo, afirma que a "tentativa mais recente de se ultrapassar o processo como forma ideal de transação judicial tem sido feita pela mídia. O procedimento ritualizado do direito, representado pelo processo, parece arcaico quando a imagem da tela e as novas técnicas de comunicação oferecem muitas outras possibilidades" (1996a:231).

Parte dos estudos sobre a judicialização das relações sociais que caminham em direção à teoria de usurpação do poder que emana da representatividade popular inclui entre as causas do fenômeno possíveis excessos cometidos pela mídia na sua relação com o mundo do direito. É preciso observar, no entanto, que essa visão pessimista encerra um conceito de cultura jurídica centrado exclusivamente no direito formal (estatal). Indo mais longe, considera a existência de uma única cultura jurídica formada por aqueles que dominam o conhecimento técnico do direito, de sua intrincada e complexa rede de regras, leis, regulamentos etc. Não cabe aqui possíveis argumentos de que o domínio desse conhecimento técnico é elitista. Contudo, é importante considerar a existência de uma pluralidade de culturas ou subculturas, que se manifestam de diferentes maneiras na sociedade contemporânea. É fundamental verificar como as diferentes culturas jurídicas são construídas e percebidas, pois os indivíduos "geram as significações a partir da situação que eles ocupam na estrutura social. Em diferentes momentos, o indivíduo é rodeado por um fluxo de significações culturalmente modeladas e que lhe são acessíveis do exterior; fluxo que influencia a maneira pela qual ele ordena experiências e intenções" (Hannerz, 1992). Ou seja, o aspecto biográfico do indivíduo revela o seu espectro de experiências precedentes. Mas, o que isso tem de importante para a análise da questão da cultura jurídica e da mídia?

\section{A Cultura Jurídica}

Quando se discute a idéia da presença do direito na sociedade, surgem diversas questões, dentre elas a amplitude do conceito de cultu- 
ra jurídica ${ }^{2}$, que comporta variadas definições e perspectivas de análise. Sob um ponto de vista geral, a cultura jurídica é o "conjunto de técnicas de exposição e de interpretação empregado pelos operadores do direito - tanto em âmbito técnico quanto teórico - e o conjunto de ideologias correspondentes à função do direito que é expresso por suas técnicas" (Dictionnaire Encyclopédique de Théorie et Sociologie du Droit, 1993:139). A cultura jurídica não se confunde com o pensamento, a dogmática ou a doutrina jurídica. O pensamento jurídico compreende "uma hipótese ou um conjunto de hipóteses produzidas, seja pelos técnicos do direito, seja por outros operadores, concernente à autodenominada natureza do direito, suas características estruturais constantes, sua função". A dogmática encerra a idéia de "uma fase historicamente determinada dos acontecimentos da cultura jurídica moderna, em especial do Ocidente [...] —, a maneira de expor e de tratar o direito positivo em relação a categorias conceituais como 'negócio jurídico', 'autonomia da vontade' e 'ato jurídico'". E, por fim, a doutrina é entendida "como uma parte constitutiva, mas não exaustiva, da cultura jurídica, mais exatamente a parte que procede à especificação e à interpretação do sistema dogmático dos conceitos" (ibidem). Todas essas definições se encaixam em uma perspectiva que leva em conta o ordenamento jurídico formal.

A particularidade do conceito do objeto deste estudo pode, ainda, ter como base a acepção antropológica do termo. Neste caso, considera-se a cultura jurídica como "um elemento do costume de uma comunidade submissa às regras jurídicas comuns". Essa perspectiva se traduz na expressão inglesa "knowledge and opinions about law" e indica aquilo que se define como cultura jurídica externa, em que se procura analisar o desvio e o distanciamento entre o direito formal e o direito efetivamente praticado. "Em outros termos, o estudo da cultura jurídica formal revelou-se uma premissa indispensável para os estudos sociológicos sobre a eficácia e a efetividade". Uma segunda acepção do termo, definida também como cultura jurídica interna, trabalha o "conjunto de valores, de princípios, de ideologias (relativas ao direito) e de léxicos próprios às profissões jurídicas dos operadores do direito" (ibidem).

Para a expressão cultura jurídica interna, significados variados podem ser identificados. Tendo como sujeito os juristas, ela seria o conjunto de doutrinas e sistemas conceituais por eles elaborado para dar consistência ao ordenamento jurídico; os modelos de raciocínio em- 
pregados por esses técnicos - do ponto de vista doutrinário ou jurisprudencial; o conjunto do léxico especializado que eles utilizam não coincidindo com a linguagem ordinária; os valores por eles compartilhados, em especial aqueles objetivos expressos de política do direito, e a interpretação dos textos normativos perpetrada pelos operadores do direito. Por fim, tem-se aquilo que Weber tratava como a classe dos juristas, formada por técnicos que compartilhariam um corpo de interesses específicos (idem:140).

Dessa forma, pode-se avançar na discussão da cultura jurídica como um elemento determinante e particular no funcionamento dos sistemas políticos modernos. O termo pode ser compreendido quando "os autores pretendem explicar as diferenças nacionais e locais do pensamento ou da prática jurídica sem saber precisamente quais podem ser os fatores explicativos (cultura jurídica comparativa)" (ibidem). A maior parte da literatura em sociologia do direito define a cultura jurídica como "valores e atitudes que ligam o sistema em um conjunto, e que determinam o local ocupado pelo sistema jurídico na cultura da sociedade considerada como um todo" (idem:141). Essa definição introduz a distinção entre valores e atitudes e o direito por parte do público e dos operadores jurídicos.

\section{A cultura jurídica das instituições legais}

A obra que difundiu o conceito de legal culture (cultura jurídica), The Legal System, tem como perspectiva uma análise sistêmica do direito, privilegiando não seus aspectos "internos", mas sim, "externos". Desse modo, o jurídico seria apenas um dos diversos sistemas existentes na sociedade, sendo estes sistemas diferenciados daqueles que lhe dariam significado. O sistema jurídico seria influenciado pelo comportamento social, de maneira que aspectos subjetivos teriam papel determinante na sua formação.

A estrutura desse sistema comportaria: 1 . as forças sociais e legais que o pressionam constantemente; 2 o próprio direito (suas estruturas e regras); 3. o impacto do direito sobre o comportamento dos indivíduos dentro e fora de seu cotidiano (Friedman, 1987). Friedman procura conciliar as regras e engrenagens típicas do sistema jurídico (inputs) com os estímulos vindos do exterior (outputs). Ao estabelecer tais relações, o autor constrói um conceito que tem por finalidade observar aspectos subjetivos do direito. Todavia, essa preocupação se acaba es- 
pelhando nos institutos legais oficiais, e na estrutura institucional do Estado e dos seus operadores jurídicos. Não há nessa concepção um reconhecimento de "lógicas de justiça" diferenciado daqueles peculiares aos operadores do direito. Nesse esquema, o comportamento legal é uma mistura de comportamentos baseados em interesses próprios (resposta a sanções e motivos morais) (idem).

Os limites da perspectiva de pesquisa de Friedman e sua ligação com os fenômenos "legais" em um sentido mais convencional, centrado nas instituições jurídicas, políticas e órgãos administrativos, podem ser verificados em sua exposição de motivos: "Neste livro, nós queremos examinar como as instituições legais se relacionam com a socieda$\mathrm{de}^{\prime \prime}$ (idem:10). A partir deste ponto, pode-se verificar sua analogia com um outro conceito desenvolvido por Almond e Verba (1965): cultura política. Na definição destes autores, o sistema político é visto como "internalizado na cognição, sentimentos e avaliações de sua população" (Friedman, 1987:15). Essa forma de entendimento dos aspectos culturais do direito contempla o conjunto de atitudes e valores em relação ao "direito jupiteriano" ${ }^{3}$, como descreve Ost (1996). A percepção do aspecto subjetivo do justo existente em uma sociedade é construída e analisada tendo como base a concepção moderna da ciência jurídica, que, por sua vez, é marcada pela "abstração e axiomatização do direito, subjetivismo, simplicidade e segurança das relações jurídicas, separação da sociedade civil e do Estado, universalismo e unidade da razão jurídica" (Arnaud, 1998:152).

Essa análise trata do conjunto de idéias, atitudes, valores e expectativas em relação ao direito, que é sustentado pelo público ou por parcela deste. A definição clássica de cultura jurídica, no sentido sociológico do termo, vem de Friedman (1987). A cultura jurídica, então, refere-se ao conhecimento público de atitudes e padrões de comportamento em relação ao sistema legal. Segundo Cotterrel (1997:15), tal conceito, inicialmente, aparece relacionado a idéias e modelos de comportamento. Posteriormente, surge como algo ideal, em que a cultura jurídica consiste "em atitudes, valores e opiniões sustentados na sociedade em relação ao direito, ao sistema jurídico e suas diversas partes". Pode-se, ainda, citar o próprio Friedman: "Como cultura jurídica consideramos as idéias, valores, atitudes e opiniões que as pessoas sustentam, em determinada sociedade, em relação ao direito e ao sistema legal" (1994:117). O autor afirma, ainda, que a idéia de cultura jurídica é uma fonte do direito, pois está relacionada com o impacto 
deste na sociedade. O termo cultura jurídica também é discutido na literatura pelas acepções "legal consciousness" ou "knowledge and opinion about law" (ibidem). O conceito de cultura jurídica pode, além disso, ser medido via questionários que procurem identificar as idéias, atitudes e opiniões dos indivíduos em relação ao direito. Ou por meio da observação daquilo que as pessoas fazem e de suas atitudes diante do que vêem (ibidem).

Tal conceito, é nítido, não se mostra avesso a controvérsias, em especial no que se refere à sua mensurabilidade. Cotterrel (1997) afirma ser muito vaga a definição de cultura jurídica proposta por Friedman, assim como o próprio conceito de cultura em geral. O problema não estaria no trabalho do autor, mas no aspecto amplo do termo, que encerraria os seguintes problemas: a definição do conceito; as variações da cultura legal e de suas relações; a significância causal dos seus mecanismos; o significado exploratório do termo. Para analisar o conceito, haveria dois caminhos. O primeiro seria a comparação e o reconhecimento de diversas tendências históricas ou movimentos não restritos aos limites do sistema do Estado-nação. $\mathrm{O}$ segundo, a compreensão do seu pluralismo, a partir de uma perspectiva própria das ciências sociais. O que se questiona é se a cultura jurídica, dada a diversidade dos níveis de vida social, pode ser uma ferramenta útil para a sociologia do direito (idem).

É certo, porém, que o conceito de cultura jurídica serve de apoio ao fenômeno social, podendo ser aplicado em ambientes nos quais as relações são de difícil definição estrita. Além disso, segundo Cotterrel, muito do que se trabalha em cultura jurídica poderia ser melhor explicado pelos efeitos que ela tem em comum com o conceito de ideologia legal (legal ideology). Tal noção poderia ser analisada por meio das práticas profissionais do direito; pelo seu impacto, via exercício profissional, nos contextos institucionalizados em que a doutrina legal é desenvolvida e aplicada, tornando-se perceptível à consciência dos indivíduos. Para o autor, a concepção de ideologia legal pode enfatizar a ligação entre poder social e correntes de pensamento e de crença.

Dessa maneira, cultura jurídica, conforme a acepção de Friedman, poderia ser utilizada em situações e lugares específicos, "onde possam existir circunstâncias em que é apropriado identificar a cultura jurídica como uma categoria empírica, em lugar de tratá-la como mera construção ideal" (Cotterrel, 1997:25). Isso seria operacionalizado 


\section{Vicente Riccio}

através do isolamento de agregados culturais relevantes em pequenas escalas, pela construção de tipos ideais. Tal proposta seria viável nas situações em que não se considera a análise de sistemas estatais legais, mas, sim, de uma pluralidade de sistemas regulatórios nas sociedades contemporâneas. Enfim, daquilo que se resumiria como o espelho dos diversos tipos de cultura legal em uma dada sociedade (idem).

A proposta de Cotterrel é uma crítica à perspectiva de se trabalhar o conceito de cultura jurídica em relação a valores, atitudes e práticas dos operadores do direito. A interação dos indivíduos, na perspectiva do autor, surge como um traço específico e importante da análise da cultura jurídica. Para ele, a contextualização é extremamente importante para a compreensão do fenômeno, em especial das condições de uma "consciência legal popular", que pode ser medida em espaços sociais específicos. Assim, a idéia de cultura jurídica poderia ser compreendida em um espectro de diversas culturas, em que se abre espaço para a contingência e a contextualidade.

Esse posicionamento nos remete a Almond e Verba que, nos anos 60, analisaram o conceito de cultura cívica (tema da teoria política clássica) a partir de uma perspectiva empírica, incorporando à sua pesquisa elementos de psicologia social, em blocos explicativos que integram instinto, hábito, sentimento e atitude. No trabalho de Almond e Verba (1965), a perspectiva empírica manifesta-se, principalmente, na utilização de métodos quantitativos para a análise dos aspectos normativos da democracia. $\mathrm{O}$ fator determinante da pesquisa seria a cultura da participação: "A cultura política de uma nação é a distribuição particular de modelos de orientação a objetos políticos entre os membros de uma população". Os autores acentuam o problema da orientação dos indivíduos em relação ao sistema político pela observação de quatro fenômenos: a percepção sobre nação e sistema político; as opiniões sobre estruturas políticas, elites e papéis de policy making; o conhecimento do sistema político; a forma pela qual o indivíduo se percebe como parte do corpo político.

A perspectiva de pesquisa colocada na obra de Almond e Verba é centrada nos aparelhos formais e não abre espaço para uma percepção dos diversos loci de cultura política e jurídica das sociedades contemporâneas. Cabe ressaltar que o trabalho dos dois autores foi criticado por seu funcionalismo e pela adoção da idéia de cultura cívica an- 
glo-saxônica como a única que realizaria o ideal democrático. O parêntese é necessário para que sejam analisados os aspectos culturais do direito, pois Almond e Verba, ao estudarem a percepção dos indivíduos, desconsideram a interação entre eles, privilegiando apenas um lado da questão: o sistema político formal.

\section{A cultura jurídica e o problema mídia versus direito}

Como o conceito de cultura jurídica "inaugura" a análise de aspectos subjetivos sobre o direito, podemos confrontá-lo com o tema da mídia e do direito, isto porque existe uma pluralidade de situações de apresentação do direito na mídia. Representações simbólicas do justo aparecem na mídia sob formas diversas: em críticas à ineficiência da prestação de serviços de saúde pública no país (tema da injustiça social); no típico "tira" de um filme policial, que não segue o regulamento da instituição, mas consegue resolver o problema através da perspicácia; na análise da morosidade de um processo de cassação de mandato de um parlamentar acusado de corrupção (moralidade pública). Nos três casos há uma crítica a possíveis injustiças causadas pelo cumprimento de regras processuais - a imagem de que a justiça é um fim em si mesma. Longe de se querer criticar a mídia, em via única, pela sua busca por "transparência total", deve-se levar em conta a multiplicidade de situações em que o justo ou o legal podem ser tematizados nos diferentes veículos de comunicação de massa.

Nesta análise cabe, ainda, uma outra questão: os julgamentos dos indivíduos sobre o justo, o crime, a lei ou a ordem baseiam-se exclusivamente na sua percepção sobre os institutos legais? Neste ponto, o conceito clássico de cultura jurídica é falho, pois reconhece como válidas apenas as atitudes dos indivíduos em relação a esses institutos. Ao se trabalhar a questão sob esse único ponto de vista, perde-se o reconhecimento de que "conceitos de justiça" ou idéias sobre o direito são múltiplos e diferenciados, variando de acordo com o tipo de interação com o sistema legal. A resolução de brigas de vizinhos em um Juizado Especial, o inquérito em uma comissão parlamentar ou a abordagem de um indivíduo em uma batida policial são marcados por diferentes tipos de interação e diferentes percepções sobre o sistema legal. Dificilmente as pessoas elaboram um conceito particular de "buracos negros", mas do faxineiro ao astrônomo-chefe de um observatório, todos terão uma idéia de "justiça", idéia esta que não será concreta e idealmente relacionada com o sistema legal oficial. 
A análise elaborada pela sociologia do direito observa a relação entre a mídia e o direito como um processo de usurpação levado a cabo pela primeira contra o segundo, pois a mídia não respeitaria as garantias processuais dos indivíduos e deslocaria o discurso da justiça de seu locus tradicional: o pretório. Todavia, a relação entre direito e mídia não se prende somente a essa questão. Ela a transcende. É certo que, em muitos casos, a usurpação ocorre, gerando sérios problemas, mas a relação não se limita a tal fenômeno. A mídia é parte da vida social e um fator cultural no mundo contemporâneo, participando do cotidiano dos indivíduos, como "um tópico e como uma atividade estruturante e estruturada pelos discursos nos quais é discutida" (Alasuutari, 1999:6). Ela possui um lugar no mundo contemporâneo, caracterizado pela diversidade de discursos.

Diante de tal diversidade simbólica, parece-me inadequado analisar a relação mídia versus direito apenas pela ótica do discurso jurídico oficial. É preciso levar em conta percepções próximas a esse direito, da mesma maneira que discursos em oposição aos seus princípios. A mídia deve ser vista como um espaço de contextualização das diversas percepções sociais sobre justiça. Para a análise de um espaço que comporta diversas formas e discursos, o conceito mais adequado é o de folk knowledge.

\section{FOLK KNOWLEDGE}

A análise do tema da cultura jurídica, como vimos até aqui, é sistematicamente pautada por uma perspectiva centrada no direito formal, que leva em conta apenas a relação dos indivíduos com a lei instituída. Essa visão oficialista, que desconsidera os aspectos simbólicos de justiça concebidos pela sociedade, também predomina nas teses que tratam da relação entre mídia e direito. Neste trabalho, no entanto, procuro mostrar que a idéia do justo subsiste em um conjunto de imagens e percepções exteriores ao mundo jurídico formal, apresentando variações manifestadas de acordo com a experiência de vida e a interação entre os indivíduos. Tais situações são ampliadas pela existência de diversas subculturas no interior das sociedades complexas que compõem o mundo atual (Hannerz, 1992).

A análise desse mundo exterior à lógica dos operadores do direito, dos códigos, das regras e dos intrincados institutos processuais pode ser feita a partir de um importante conceito: o folk knowledge. Por folk

\section{4}


knowledge entende-se "a compreensão diária, dada como certa, que molda a percepção das pessoas, o pensamento, as ações e as reações a eventos e situações" (Steiner et alii, 1999).

Ao trabalhar a idéia de folk knowledge como um fenômeno legal, procuro identificar o direito na sociedade. Reconheço que os cidadãos não são somente pressionados por leis impostas do exterior. Tal perspectiva leva em conta o direito construído na vida cotidiana, nas expectativas baseadas no senso comum dos indivíduos, no qual instâncias exteriores ao Estado trazem uma simbologia diversa do que é considerado direito oficial. Isso não significa, entretanto, que o direito estatal tenha um opositor no folk knowledge. O folk knowledge "algumas vezes é contrário, outras se direciona para o direito estatal. Ele é por si mesmo integrado ao direito oficial, tanto constitutivo como crítico em alguns momentos" (idem). As interações dos indivíduos revelam diferentes tipos de comportamento em relação ao direito oficial, que pode ser reconstruído, criticado e registrado.

No trabalho intitulado The Common Place of Law, Ewick e Silbey procuraram estudar as formas pelas quais as pessoas descobrem e raciocinam sobre o direito, as concepções sobre o mundo jurídico que levam o indivíduo a recorrer a um advogado para reclamar do "cachorro do vizinho", e como os americanos compreendem o direito em suas vidas, incluindo o grau em que utilizam a lei, entusiasticamente ou não. Em suma, as autoras buscaram entender o que a legalidade significa no cotidiano do cidadão norte-americano, baseando a pesquisa no relato de situações e experiências do dia-a-dia das pessoas:

\footnotetext{
“Experiências de lugares-comuns e imagens do direito variam. Algumas vezes, o direito aparece como majestático, remoto, e uma força transcendente governando negócios humanos de um planalto alto e distante. Outras vezes, o direito parece uma arena humanizada na qual as pessoas lutam umas com as outras em encontros sérios e bem-humorados, mais ou menos habilmente, para todos os tipos de propósitos sublimes e afetuosos" (Ewick e Silbey,1998:15).
}

Embora aparentemente distante, o direito envolve a paisagem social e pode ser visto nas cortes de justiça, nas regras dos estacionamentos, no casamento, no ato de pagar o aluguel ou reclamar do defeito de um produto, na ronda policial etc. Sua presença pode, ainda, ser facilmente detectada na mídia, conforme ressaltam Ewick e Silbey: 
Vicente Riccio

"O direito parece ter uma proeminente presença cultural, ocupando boa parte de nossa mídia mais popular, fornecendo um trunfo tanto para o noticiário quanto para a indústria do entretenimento. Nós assistimos a processos reais e fictícios na televisão, e freqüentemente somos incapazes de distinguir fato de ficção. Comungamos piadas sobre advogados. Escutamos relatos sobre crimes e criminosos no noticiário noturno. E, se o sucesso de autores como John Grisham é alguma indicação, milhões de nós devotam horas do seu tempo de lazer a ler histórias sobre crime, cortes, advogados e direito" (idem:16).

O mundo jurídico é vivido de maneira estranha e familiar. É um evento constante na vida dos indivíduos. Para alguns, essa situação representa uma erosão do poder do direito; para outros, é um sinal da fragmentação e pluralidade da cultura pública, extremamente importante na análise do mundo jurídico cotidiano. A legalidade, vista como uma característica emergente da vida social, atuando no centro desse mundo, "não é sustentada somente pelo direito formal da Constituição, das regras legislativas, das decisões das cortes ou de demonstrações explícitas do poder do Estado, como, por exemplo, nas execuções. Ao contrário, a legalidade é duradoura, pois depende e invoca esquemas da vida cotidiana" (idem:17). No exercício da vida cotidiana, os indivíduos respondem às situações em função das características recorrentes de suas interações sociais, e não o fazem a partir de critérios exclusivamente construídos com base no mundo da política ou do direito formal, por isso:

"Essas categorias folk são construídas e utilizadas para ordenar e dire-
cionar o trabalho legal. Então, por depender da lógica social comum e
das categorias e normas culturais legais, a ação legal reflete, e também
reproduz, categorias não legais da vida diária. Embora possamos fa-
lar sobre o direito como se fosse uma entidade singular e distinta, nós
aprendemos que não podemos observá-lo fora de suas manifestações
materiais, históricas e particulares, além de variáveis" (idem:18).

Ewick e Silbey descrevem a importância do contexto social da interação individual nas três situações típicas em que o folk knowledge é reconstruído em uma corte de justiça: diante do direito (before the law); com o direito (with the law); contra o direito (against the law). O que se verifica é a pluralidade de situações em que a legalidade se apresenta, sendo, ao mesmo tempo, um componente estrutural e um espaço aberto para as percepções dos indivíduos sobre suas experiências de 
vida. Na situação de legalidade "diante do direito", ele é distinguido como uma esfera separada da vida ordinária, descontínuo, distinto, autorizador e previsível. O sistema legal é visto de maneira tradicional, como formalmente ordenado, racionalizado e como um conjunto hierárquico de normas e procedimentos. Os pesquisados consideram-no rígido e impermeável à ação individual. Mesmo nessas situações, as pessoas apresentam aceitação e lealdade ao sistema legal; acreditam na justeza dos procedimentos, embora não sigam seu juízo em relação aos resultados (idem).

Na situação classificada como "with the law", tem-se a exposição à contingência. Vê-se o direito como uma arena em que as regras preexistentes são descartadas e outras são inventadas para servir um corpo maior de interesses e valores, com predominância do interesse individual e reforço da idéia de ganhos estratégicos. Há um limite poroso entre direito e vida cotidiana. Em vez de ser descontínuo à vida diária, o direito é estruturado por ela. Nessa situação, os entrevistados demonstraram menos compreensão quanto à legitimidade dos procedimentos legais em relação ao seu desejo de atingir determinados objetivos (idem).

Por último, na terceira forma de se participar da legalidade, há a situação em que os indivíduos se colocam contra o direito. Neste caso, há um descompasso entre os indivíduos e as prescrições do mundo legal. As pessoas buscam uma "pausa" no poder do direito, procuram escapar momentaneamente à sua influência e poder. Essa resistência apresenta diferentes motivações, podendo ser fruto de questões como defesa da dignidade e vingança. Em certos momentos, a intenção é evitar o poder e os custos do direito. Contudo, a conduta adotada não é a do cinismo, embora os atores sociais se valham de pequenos subterfúgios e violações das normas estabelecidas.

A análise da relação entre mídia e direito baseada em uma dualidade que classifica a primeira como informal e o segundo como formal não leva em conta a pluralidade de situações em que os indivíduos estão inseridos, bem como suas experiências cotidianas. É certo que a cobertura jornalística envolvendo questões relativas ao direito pode cometer excessos, como no caso da Escola de Base ${ }^{4}$. Ao mesmo tempo, no entanto, o trabalho da imprensa pode ser o catalisador de demandas sociais capazes de reformar o Judiciário, como se verificou na divulgação das imagens do abuso policial cometido na Favela Naval, 
em Diadema ${ }^{5}$. O projeto de tipificação do crime de tortura no país tramitava no Congresso Nacional havia vários anos. Após a transmissão das imagens pelo Jornal Nacional, uma onda de indignação espalhou-se por todo o Brasil e o crime de tortura foi tipificado rapidamente pelos parlamentares ${ }^{6}$. Assim, não parece satisfatória uma análise da relação entre mídia e direito sob esse prisma do dual ou que leve em conta somente a perspectiva do poder da mídia como algo "nefasto" e "usurpador" da representatividade popular.

Mesmo no caso das cortes, há diferentes tipos de interação e percepção do direito, além de ser muito pequena a compreensão dos institutos jurídicos por parte dos indivíduos. Na análise realizada por Tyler (1997) foi verificado que as pessoas presentes às cortes de justiça não possuíam conhecimento dos institutos processuais nem tinham a vitória jurídica como maior preocupação. Na verdade, o que mais as absorvia era a questão da imparcialidade. Além disso, as pessoas que lá compareciam tinham a confiança como ponto fundamental da sua relação com o Judiciário.

Em outros trabalhos se constata que o indivíduo, ao ter seu primeiro contato com o sistema legal, pouco conhece da natureza dos intrincados procedimentos jurídicos, seja em um Tribunal da Infância em Bobigny (Israel, 1999) seja em um Juizado Especial no Rio de Janeiro (Werneck Vianna et alii, 1999). Ao mesmo tempo, porém, o direito exterior ao mundo da dogmática está presente na sociedade. Uma série de imagens do mundo do direito e da legalidade integra-se ao cotidiano da vida social, e a mídia é um dos principais loci em que se observa tal situação. O noticiário é repleto de informações sobre crimes, canais especiais transmitem julgamentos nos Estados Unidos (Lassiter, 1996) e obras culturais tratam de temas relativos à lei e à ordem.

Reconhecida como um conceito pertinente à vida cotidiana, de que forma a legalidade poderia ser útil à compreensão de fenômenos como um programa do tipo reality show? Tal questionamento é importante para a definição da perspectiva de análise de um programa de televisão que tenha por objeto o direito ou um tema correlato. O que se pretende considerar é a utilização do conceito de folk knowledge como ferramenta apropriada para a verificação do mundo contraditório de elementos e instituições existente no exterior do sistema jurídico formal. Essa perspectiva parece mais adequada que a idéia de cultura jurídica defendida por Friedman (1994), sustentada em um 
aspecto formalizado do "quadro de atitudes" dos indivíduos em relação ao direito instituído. Como medir essas atitudes em relação ao sistema legal quando concepções do justo existem fora do mundo sistêmico e se relacionam de maneira não-linear, afastando-se ou aproximando-se do mundo formal de acordo com a situação? Uma perspectiva alinhada à concepção de Friedman não se mostra apropriada para a análise de um reality show que apresente o tema do direito por meio de linguagem popularizada ou, mesmo, caricata.

Além disso, o aspecto contingente não é reconhecido pelo autor, assim como o quadro de experiências individuais que se manifestam de acordo com as circunstâncias. Os três tipos de situação junto às cortes, conforme descrito por Ewick e Silbey (1998), demonstram a diversidade de realidades em que o direito é reconstruído. Essa perspectiva dá sustentação à proposta de análise do tipo de situação em que as construções folk se apresentam na mídia e a reação do público a esses momentos específicos. A relação entre direito e mídia é complexa e, como será verificado na próxima seção, não existe apenas um "cabo-de-guerra" entre os dois campos. Há pontos de distanciamento, mas também de proximidade entre os dois mundos, visto que ambos são elementos indispensáveis ao exercício da democracia moderna.

\section{O DIREITO E A MÍDIA}

Os temas da cultura, da mídia e do direito encontram-se presentes em diversos tipos de situação e de análise sociológica. Mas como tratar suas especificidades? Essa presença pode ocorrer no campo da dogmática por meio dos códigos, leis, decretos e regulamentos que tratam da questão da comunicação. Mas pode, também, manifestar-se nos produtos da comunicação de massa, como noticiários e programas de TV e rádio ou da imprensa escrita; nos produtos culturais e nos aspectos simbólicos da vida cotidiana associados à percepção do justo nas sociedades contemporâneas. Uma questão interessante é a discussão daquilo que se constitui como cultural em relação ao jurídico. Não somente o direito escrito e racionalizado faz parte do que chamamos de cultura jurídica, mas também o direito exterior ao sistema. Esse mundo exterior pode ser analisado de diversas formas, tomando-se por base a compreensão do papel dos institutos legais, a percepção da idéia de justiça e/ ou o aspecto cultural das interações jurídicas do cotidiano. 


\section{Vicente Riccio}

A relação entre o direito e a mídia, é certo, apresenta um forte conteúdo cultural. De um lado, existe uma cultura marcada pela rigidez da forma, do tempo correto da fala, da presença de uma instância física definida; de outro, uma grande informalidade, um tempo indefinido e uma "instância virtual". Essa distinção entre duas faces da relação acarreta também um conflito de culturas subjacentes a elas. A cultura dita "formal", relativa aos operadores do direito, estaria em contradição com a cultura legitimada fora do Estado. Outro componente marcante para a análise do conflito entre as duas esferas é o público, responsável pela interpretação do mundo jurídico tanto dentro quanto fora da mídia.

Ao se examinar essa tensão entre cultura formal e informal, é preciso ter em vista a diversidade de situações em que ela se apresenta. Como analisar a questão mídia versus direito? Qual a sua relação com a idéia de cultura jurídica? A idéia de cultura jurídica é válida ou deve-se considerar a existência de várias culturas? O processo ocorre em uma via de mão única, com uma invasão do mediático no jurídico? Qual é o papel dos indivíduos nessa relação? O "senso comum" sobre o direito seria indissociável da mídia? Não seria este um fator cuja presença causa maiores questionamentos que uma suposta violação da cultura jurídica?

A pesquisa a respeito do tema inclina-se, basicamente, sobre a tensão existente entre os mundos do formal e do informal, de suas peculiaridades. Uma das preocupações dessa investigação é a análise da desnaturação do aspecto formal do jurídico por parte do mediático. Todavia, os trabalhos que tratam da questão apresentam perspectivas muito diferentes entre si. Podemos observar a tensão entre o direito e a mídia como uma crise da democracia contemporânea (Garapon, 1996a; 1996b; 1996c; Garapon e Salas, 1997; Salas, 1998); uma invasão do espaço judicial pelas câmeras de TV (Lassiter, 1996); uma cobertura de notícias sobre crimes cujo impacto ambiental é grande, mas não gera apelo mediático (Lynch et alii, 2000); uma relação entre o direito e a literatura (Aristodemu, 1993); pela ótica do sistema de justiça criminal como um objeto da cultura popular (Newman, 1990); da justificativa do veredicto de jurados na mídia (Marder, 1997); dos efeitos da publicidade anterior a julgamentos e seus veredictos (Bruschke e Loges, 1999); do tratamento legal de publicidade anterior a julgamentos (Chesterman, 1997); da distorção da verdade e da confusão entre fato e ficção em produtos culturais, e de suas implicações éticas (Cowan, 
1998); das conexões entre a compreensão cotidiana do jurídico através da mídia e da sua relação com a ação legal (Steiner et alii, 1999).

O estudo do tema comporta uma ampla gama de caminhos para análise, que tornam relativa a idéia de tensão entre mídia e justiça, formal e informal e localizado e não-localizado como únicos pressupostos possíveis de pesquisa. Não obstante essa colocação, a partir deste momento se descreve a forma como a tensão entre os dois campos é apresentada, centrando-se a análise, inicialmente, no aspecto da distinção entre o tempo do processo e o tempo da mídia.

Os meios de comunicação, em função da sua capacidade de atingir diversos pontos, instantaneamente, oferecem o contato direto com a realidade, sem nenhum obstáculo, sendo que o poder da imagem se dirige com toda a força para os sentidos. A linguagem processual interpõe diferenças entre a mídia e a justiça. O contraditório é a "alma" do processo, já que nele todas as partes envolvidas têm igual direito de manifestação, tornando imprescindível seu aspecto formal. E a garantia à palavra em um tempo determinado é incompatível com o instantâneo. A mídia, diferentemente do direito, opera com a lógica da rapidez. Mostrando os fatos quase que em tempo real, ela nos liga a diversos pontos do globo, indistintamente. Sua essência não comporta a rigidez formal do processo.

A justiça tem a tarefa de reunir as partes e reconstruir os fatos em um espaço comum, conforme define Garapon:

"O primeiro ato de soberania da justiça — e possivelmente o único é o de juntar as partes sobre seu território, que é de resto sempre o mesmo: o universo fechado da sala de audiência. Aquele obriga todas as provas a adotar a forma da narrativa e a se entregar a um exercício apropriado em um lugar convencional" (Garapon, 1996c:270).

Ou seja, o acesso ao processo implica a adoção de uma linguagem referenciada no tempo, em um momento específico à argumentação, e a inserção simbólica dentro de um território: a sala de audiência. $\mathrm{O}$ garantidor dessa inserção, bem como do momento, é o corpo político (soberano), que o faz através da formalização legal.

Já a mídia tem uma perspectiva diversa, por não se encontrar nela um tempo determinado; tudo se reporta a uma multitemporalidade e não 
Vicente Riccio

existe um espaço definido ou disciplina de argumentação. Não há garantia para o contraditório:

"Assim, a televisão manifesta sua vontade de reparar, de reunir as famílias, de proceder aos apelos das testemunhas, de supervisionar o trabalho de todas as instituições. Nesse sentido, nós podemos falar de 'deslocalização' de certos processos na mídia: os debates não são mais circunscritos a uma instância física - o pretório - na qual as regras são firmemente estabelecidas — o procedimento - , mas se desenvolvem fora dos muros, ou melhor, eles não têm lugar próprio, à semelhança de certos mercados financeiros, e podem ser mais do que regras" (ibidem).

Se o apelo emocional da televisão, um dos aspectos da mídia, desloca o debate da instância física - o fórum - e elimina a rigidez das regras processuais, a inversão da perspectiva do ato de julgar é um fato que se sucede com o público receptor. A razão pela qual tal fenômeno ocorre está nos fundamentos do processo: sua rigidez permite que os fatos sejam reconstruídos sobre uma determinada lógica - conhecida previamente pelos operadores das normas. A rigidez é um princípio, e princípios, teoricamente, não se alteram em relação aos fatos. Cabe, ainda, o registro de que a presunção de inocência é um dos fundamentos do processo e, pela sua lógica, não deve ser alterada em relação às circunstâncias. A mídia não lida com a mesma perspectiva do processo, pois sua proposta é a da verdade imediata, de entendimento mais acessível que as intrincadas e abstratas regras processuais.

Pode-se indagar a respeito da tentativa de se elaborar uma teoria "generalista" da relação entre a mídia e o direito. Não se deve considerá-la apenas como uma violação das "regras processuais", ou mesmo uma usurpação indevida de um espaço estatal. É certo que tal situação ocorre com freqüência, mas não significa que seja a única possível. O processo, como uma forma indispensável de resolução de conflitos, está preso a uma lógica interativa que privilegia o tempo e o espaço. A execução de seus comandos faz-se no momento da audiência, e difere do tipo de interação da mídia. Esta, que Thompson define como quase-mediada, se caracteriza pela separação da produção do contexto da mensagem da recepção; de sua disponibilidade no tempo e no espaço; por orientar-se para um número indefinido de telespectadores; por ser monológica (Thompson, 1998). 


\section{O Campo de Proximidade entre Mídia e Direito}

A natureza da mídia diferencia-se em muitos aspectos da do direito, mas, por outro lado, ambas se aproximam em diversos pontos. A relação do corpo do direito com a mídia não é somente uma questão de "oposição". Os pontos de proximidade são vários e exigem um novo olhar para a interpretação "negativa" que comumente se apresenta na análise da relação entre eles. Portanto, a proximidade dos dois é também um fato, e como tal deve ser considerado.

Essa convergência, demonstrada em Why Law Is Like News, identifica pontos de proximidade entre esses dois campos, e não apenas sinais de oposição. Dentre aqueles que indicam uma convergência, está o discurso, pois este dá significado à criação de "subjetividades sociais, organização prática e ordem social" (Ericson, 1996:196). A justificativa está nos discursos especiais produzidos pelas instituições, que, por sua vez, estabelecem relações sociais, determinam quem tem o poder da fala e quem é a audiência, além de fornecerem formatos para a comunicação. Em suma, "o discurso é o direito, o discurso é o noticiário da mídia" (ibidem).

Ao ressaltar a dimensão e amplitude do discurso, Ericson explicita o que o direito (law) tem de semelhante à imprensa (news). A relação entre os dois mundos manifesta-se na forma como os textos são produzidos e escritos, pois "tanto os operadores do direito quanto os jornalistas trabalham em termos de orientação para um evento, resolução de conflitos, individualização e personalização de problemas, realismo" (ibidem). Além disso, os mundos do direito e da imprensa apresentam pontos comuns quanto a seus efeitos sobre as instituições e o povo. Ambos têm o poder de constituir instituições através do discurso e de afetar uma determinada organização institucional, além de apresentarem argumentos centrais para as reformas sociais. "Como agentes da ordem, estabilidade e mudança [...] direito e imprensa formam a cultura popular, constituem fronteiras, mentalidades e sensibilidades da vida cotidiana" (idem:197).

Dentre os pontos comuns aos dois mundos, Ericson destaca três que descrevem como direito e mídia apresentam semelhanças na constituição da ordem: em ambos existe a questão da moralidade; a idéia de ordem incorpora uma concepção de procedimento, um campo comum de regras que definem como, quando e onde algo vai acontecer; 


\section{Vicente Riccio}

a ordem depende da hierarquia que define o estatuto, qualidade e posição de indivíduos e idéias. Ao garantir uma "ordem", o direito e a mídia trabalham com a questão da segurança, pois, à sua maneira, asseguram um espaço de reprodução da moralidade vigente:

\footnotetext{
"Enquanto mídia e direito constituem ordem nestes termos, eles também fazem referência à segurança ou às condições necessárias para a reprodução da moralidade, procedimento e relações hierárquicas. A segurança inclui segurança moral, aquilo que é certo que vai acontecer; previsibilidade procedimental, que as coisas vão ocorrer conforme o planejado; garantias hierárquicas, em que ameaças ou perigos, como crimes sérios ou protestos públicos, estarão ausentes" (ibidem).
}

Essas semelhanças se verificam na constituição da ordem como um discurso social, pois o sistema jurídico e os meios de comunicação não oferecem apenas visões abstratas da ordem. Eles também atuam no plano da ação quando propõem ordens e comandos para influir na moralidade e na definição desses parâmetros ${ }^{7}$. Esse plano comum ao direito e à mídia tem uma carga empírica e prática, cujos limites são determinados pela lei e pela sociedade, visto que mobilizam categorias discursivas encarregadas de demarcar o certo e o errado. Essa capacidade de ajuizar o válido e o não válido resulta na indicação daquilo que é estigmatizável ou não.

Nesse quadro de características comuns existe a personalização, pois os discursos do direito e da mídia baseiam-se em pessoas problemáticas, não avaliando estruturas problemáticas que motivaram seus atos, objeto de estudo da sociologia. No âmbito jurídico, a personalização é freqüente no curso do processo penal. Existe um acusado (passível de ser estigmatizado) que, ao final de um julgamento, pode ter um crime imputado a ele e ser considerado culpado (estigmatizado). Não se resolve no quadro do processo penal a questão relativa à estrutura social do acusado ou do culpado, mas a questão factual, que pode ou não se enquadrar em uma situação específica definida pela lei.

O valor conferido à objetividade é um cânone para as esferas do direito e da mídia. O direito deve julgar com imparcialidade e neutralida$\mathrm{de}^{8}$, e a decisão deve se basear nos fatos levantados, que são julgados pela autoridade do Estado, encarnada na figura do juiz, ou pela autoridade do povo, no caso do júri. A violação desse pressuposto pode 
acarretar crise de legitimidade para o Judiciário, um dos três poderes constituintes do Estado.

A objetividade como capital da imprensa é fundamental. Sua credibilidade é construída a partir de uma ótica que privilegia a imparcialidade e a neutralidade. Isto não impede, naturalmente, que em determinados momentos esses parâmetros sejam distorcidos. O público avalia a mídia da mesma forma que confere legitimidade ou não às instituições. E essa construção da objetividade se dá de duas maneiras: no caso dos jornalistas, o elemento fundamental é a vida cotidiana; para os operadores do direito, é a lógica de seus códigos jurídicos.

No processo jurídico, o contraditório e a ampla defesa são garantias formais que permitem o julgamento de uma causa. Essa lógica dos contrários se apresenta, também, na atividade jornalística e no seu código de ética. Todavia, um ponto de diferença entre as duas lógicas é o público receptor do discurso. No caso do discurso jurídico oficial, esse público tem uma cultura restrita, baseada no conhecimento técnico de sua disciplina e derivada de uma organização profissional com alto grau de institucionalização 9 . O público do discurso mediático é, por outro lado, amplo e fluido, sendo mais suscetível à forma do discurso moralizador. A cultura profissional dos jornalistas também é forte, porém desregulamentada. Essas duas culturas que falam a públicos distintos se caracterizam por um compromisso com as idéias de objetividade, neutralidade e imparcialidade em prol do interesse público.

A presença da retórica e da emotividade é parte da argumentação dos mundos do direito e da mídia, especialmente do direito penal. O fórum é o palco onde os dramas humanos são encenados; o tribunal do júri apresenta-se, por excelência, como um espaço de ritualização e cerimonial, onde o embate retórico desperta paixões e dramatiza o crime. O júri é um espaço em que pontos centrais da natureza humana são discutidos. Amor, ódio, paixão, vingança, mesquinharia e violência são temas recorrentes em suas salas. Assim, o júri discute temas que não são apenas legais, mas também morais, intelectuais e relativos à natureza humana, mobilizando diferentes simbologias e entendimentos sobre a vida, os quais também são mobilizados pela mídia, onde se apresentam com maior intensidade, visto que o público, neste caso, é mais plural e apresenta vínculo maior com a cultura popular. Não é de se estranhar a dimensão heróica conferida aos agentes da lei 


\section{Vicente Riccio}

em seriados de TV ou a argumentação moral construída em torno de uma denúncia de corrupção, pois a mídia adota uma linguagem voltada para a razão prática, vida ordinária e senso comum.

A análise da relação entre mídia e direito, como se pode verificar, não deve partir de um único pressuposto. Não há apenas a usurpação do espaço jurídico legal pelos meios de comunicação. Existem pontos de conflito, mas também características comuns aos dois mundos. Estudar a questão por um único ângulo significa tentar compreendê-la a partir de uma de suas particularidades - a intromissão no mundo oficial. A diversidade dos produtos de mídia e das situações em que o justo é tematizado deve ser considerada. Um filme policial, um drama sobre a pena de morte, uma reportagem sobre falhas no sistema carcerário, a dramatização do crime na voz de Gil Gomes (Costa, 1992), todos esses tipos de manifestação trazem à tona diversos aspectos simbólicos que envolvem o direito na sociedade.

\section{O REALITY SHOW}

Conforme se observou no decorrer do texto, a relação entre mídia e direito deve ser analisada levando-se em consideração o tipo de programa. Por esta razão, proponho discutir como um programa de variedades pode exemplificar a relação mídia / direito. Sendo assim, a descrição do que é um reality show e suas particularidades serão tratadas nesta seção.

O reality show não é um programa de notícias tradicional, tampouco, uma obra de ficção. Sua fórmula, típica dos anos 90, foi importada dos Estados Unidos e propagou-se por diversos países. Ele invade as telas com o testemunho privado, e a TV, antes marcada pela ficção, abre-se para o mundo da intimidade. Dominique Mehl aponta alguns tipos de programa que se inscrevem nesse gênero: os reality shows de aventura, em que há uma mistura de realidade e ficção; os reality shows de intimidade, em que as pessoas expõem seus problemas privados; os de sociedade, que se caracterizam por uma intervenção do aparelho mediático e fazem uma mistura entre realidade e ficção ou se detêm somente sobre a realidade; shows que procuram valorizar o testemunho dos indivíduos comuns.

“No final das contas, o conjunto desses programas tem um ponto comum: eles mostram pessoas desconhecidas, cidadãos comuns, perso- 
nagens lambda. Assim, quer o gênero se mantenha ou não, sobre as telas, o fenômeno que ele encarna ganha o total da televisão" (Mehl, 1994:102).

Vale, também, observar a afirmação de Chambat e Ehrenberg de que

"[...] os reality shows [...] são os primeiros programas de televisão que colocam sistematicamente no centro e no princípio de sua encenação o indivíduo, sua ação e seus esforços para se realizar. Eles encarnam uma televisão que renovou a tradição do espetáculo pela novidade da comunicação e prefere tocar os indivíduos religando-os entre si a distrair as famílias unidas em um local" (1993:5).

Da mesma forma que Mehl (1994) aponta a "erosão" das fronteiras entre os gêneros televisivos e o surgimento em cena do telespectador, os autores ressaltam que o reality show consiste em um palco em que as questões do cotidiano são ensaiadas e encenadas, tendo maior presença que as tradicionais ou políticas. No reality show, a comunicação é estabelecida em razão do cidadão comum e do seu quadro de percepções. Essa característica acaba gerando um descompasso entre a lógica dos telespectadores e a dos intelectuais, e essa tensão se manifesta em uma hierarquia inferior em que se colocam os programas "menores"10.

O resultado é que os reality shows provocaram indignação entre os intelectuais, bem como entre a imprensa intelectualizada ${ }^{11}$ (Mehl, 1994; 1996). O repúdio suscitado pelo aspecto primordial desse tipo de programa - a exposição da vida privada - ganhou eco junto a uma parte significativa de alguns grupos profissionais, como os psicanalistas, que criticaram duramente a exposição pública de problemas pessoais, como alcoolismo, homossexualidade, aids, incesto, infidelidade, traição, cobiça etc.

“O meio psicanalítico, em sua grande maioria, reagiu com a mais forte hostilidade a essas encenações. Incompetência, charlatanismo, engodo, manipulação [...]. 1 - o trabalho terapêutico não pode desenvolver-se nem em um tempo curto nem em público; 2 - a espetacularização proíbe a emergência de fenômenos inconscientes e é contraditória; 3 - a psicanálise não pode ser vulgarizada (Mehl, 1996:90-91). 


\section{Vicente Riccio}

Essa tensão entre a cultura profissional e a característica e o conteúdo do programa, conforme o registro de Mehl, pode ser verificada em outro campo: o do direito. Garapon acentua esse aspecto:

"Com seus reality shows, a televisão está nos dizendo que ela não tem mais necessidade de ficção, uma vez que agora está capacitada a trabalhar com a vida real, com a cooperação das pessoas diretamente envolvidas, pessoas que, na verdade, poderiam ser qualquer um de nós. Essa é a televisão dos espectadores que querem criar os programas por si mesmos, em vez de simplesmente assistirem aos programas criados pelos outros [...]. Essa configuração do público constituída pelo drama 'judicial', na verdade, simboliza e antecipa uma forma completa de sociedade" (1996c:237).

A tensão apontada por Garapon e ressaltada anteriormente desemboca em um ponto comum que aparece em todas as opiniões emitidas sobre o tema: nos reality shows, a "valorização da palavra dos profanos, em detrimento da presença dos experts, implica que o saber 'sábio' está ausente desses postos" (Mehl, 1994:108). E isso vai ao encontro da perspectiva exposta também por Mehl em La Fenêtre et le Miroir, quando discute os cidadãos e a TV, afirmando que:

“Quando autorizamos um cidadão a se exprimir, vemos seu apetite de aprender e de compreender. Esse seria o único caminho possível de uma revolução cultural [...]. A informação é uma variante, mas existe uma outra vertente: nós não seríamos mais consumidores da televisão, mas atores [...] essa concepção é claramente aquela que coloca em marcha os criadores dos reality shows. Ela implica uma reversão dos papéis entre especialistas e profanos. Os intelectuais, os sábios, os experts, as elites são indeferidos em prol da palavra das pessoas comuns" (1992:63).

A televisão da intimidade (télévision de l'intimité) revela um enfraquecimento dos liames sociais. Pessoas à margem do sistema social e produtivo tentam obter reconhecimento, em especial aquelas marcadas pela estigmatização, seja ela social, sexual ou de gênero, cujas características particulares as tornam "exibíveis". Essa situação mostra, ain$\mathrm{da}$, uma grande dificuldade de se viver a modernidade, marcada por um enfraquecimento de corpos intermediários: "A televisão oferece suas bases esperando jogar o papel de mediadora entre o corpo social e suas elites" (Mehl, 1996:12). 
Esse tipo de programa pode ser palco de temas relativos ao direito. Pessoas que reclamam seus direitos, vítimas de violência doméstica ou de rua, criminosos que escapam do sistema judicial e outras situações em que o problema da justiça aparece individualizado e deslocado de estruturas sociais. A partir do momento em que o show de variedades apresenta em seu palco dramas humanos reais, os discursos pautados pela lógica exterior à do mundo dos operadores jurídicos são expostos a um público indeterminado. A televisão evidencia todo um processo de discussão e definição do que é justo ou não, inserido no contexto social. Essa exposição, por sua vez, traz um tipo de argumentação que, devido à sua natureza, tem inserção no debate cotidiano sobre o justo.

Ao expor, através de reality shows, problemas pessoais que reivindicam algum tipo de reparação, a mídia torna-se um canal em que a "zona cinzenta" do mundo oficial do direito e o mundo da sociedade se encontram. Tal encontro, indefinível em sua forma e resultados, mostra-se uma situação privilegiada de compreensão da realidade, na qual se expõem aspectos subjetivos sobre o justo que não são exclusivamente centrados em atitudes em relação ao direito oficial. Assim, a forma do reality show, baseada em discursos personalizados, cria momentos em que os indivíduos emitem opiniões e valores próprios, não observáveis em outros tipos de programa.

\section{CONCLUSÃO}

A análise da relação entre direito e mídia, na maior parte da literatura sobre o tema, aponta para uma invasão indevida dos meios de comunicação no campo jurídico. Resultado do crescente quadro de judicialização das relações sociais, esse fenômeno caracterizaria uma situação de concorrência indevida com a lógica democrática. Neste artigo defendo que a maior parte dos trabalhos sobre o tema peca por estudar o crescimento do jurídico na vida social por meio de uma via única e fechada - o conceito tradicional de cultura jurídica.

Ao especificar a relação entre direito e mídia, esse senso único observa o fenômeno a partir das noções de usurpação e de uma cultura jurídica oficial, calcada nas instituições políticas e nos seus símbolos. Essa perspectiva, contudo, desconsidera aquelas concepções de justiça (ou do justo) externas à lógica dos operadores do direito, aqui classificadas como folk knowledge. Sustento aqui que o conceito clássico de 
cultura jurídica não se mostra adequado à análise dessa relação baseada em uma perspectiva que privilegia o aspecto subjetivo do jurídico. Isto porque tal subjetividade não se limita à atitude dos indivíduos diante das instituições legais que governam suas vidas.

As concepções populares sobre o justo (folk knowledge) são parte do dia-a-dia dos indivíduos e manifestam-se em situações plurais. Acredita-se, portanto, que a compreensão da relação entre o direito e a mídia passa pelo reconhecimento de que tais percepções são legítimas e tanto podem mostrar distância quanto proximidade com o direito oficial. Identificar o caráter plural dessas concepções é ferramenta útil para o entendimento da relação entre direito e mídia, pois a última permite que diversas vozes expressem seus sentimentos e opiniões sobre um determinado assunto, revelando percepções sobre o jurídico em diferentes contextos sociais.

Nos meios de comunicação, devido às especificidades técnicas de cada um e à multiplicidade de formatos de programas, as percepções folk sobre o justo manifestam-se por meio de diferentes linguagens. A estrutura do reality show permite observar como são trabalhadas essas percepções individuais. As possibilidades abertas pelo show de variedades advêm dos relatos dos participantes, da experiência cotidiana, da informalidade com a qual os temas são tratados. Esse tipo de palco, diferenciado do pretório, apresenta-se como espaço ideal para a análise da multiplicidade de percepções sobre o justo. A informalidade televisiva não deve ser analisada somente pelo ângulo da sua oposição em relação ao mundo dos operadores do direito. Deve, sim, ser compreendida como característica que favorece o afloramento das concepções populares, explicitando suas contradições em relação ao direito oficial e indicando os contextos sociais a partir dos quais tais contradições são cristalizadas.

Por fim, na análise de um programa de variedades voltado para temas relativos ao justo, pode-se considerar que o fenômeno da judicialização das relações sociais comporta elementos simbólicos que não são negativos ou positivos. Estes, na realidade, convivem no interior da sociedade, em um processo dinâmico e criativo, participando da construção da legalidade, a qual não se restringe à definição dos códigos e das leis, mas tem uma grande interface com as experiências individuais e cotidianas construídas em um mundo de complexidades e incertezas. 


\section{A Lei em Tela e a Tela da Lei: O Direito e os Reality Shows}

\section{NOTAS}

1. Todas as traduções são do autor.

2. O termo cultura jurídica é utilizado em diversas línguas, dentre as quais inglês (legal culture), francês (culture juridique), espanhol (cultura jurídica), italiano (cultura giuridica) e alemão (juristische kultur) (Dictionnaire Encyclopédique de Théorie et Sociologie du Droit, 1993:140).

3. O "direito jupiteriano", segundo François Ost (1996), é aquele sistema de regras definidas pelo código que emanariam do topo de uma pirâmide, cujas normas, oriundas da razão do legislador, controlam toda a vida social. O sistema legal construído pelo código encarnaria o idéario liberal e moderno de justiça.

4. O caso da Escola de Base deu-se em São Paulo, quando os donos de uma escola infantil foram acusados indevidamente de abuso sexual contra alguns alunos. A imprensa, através de informações do delegado responsável pelo inquérito, divulgou precipitadamente o nome dos donos como responsáveis. Após o processo penal, os acusados foram inocentados e, posteriormente, indenizados por dano moral cometido pelo Estado. O debate suscitado pelo caso foi muito intenso e gerou grande comoção pública no país.

5. As cenas de abuso policial cometido na Favela Naval foram registradas por cinegrafista amador e mostram um grupo de policiais, em dias diferentes, roubando, espancando e agredindo moradores dessa favela em Diadema, cidade da região metropolitana de São Paulo. A cena mais forte registra o assassinato de um trabalhador, Mário Josino, pelo sargento Otávio Gambra, conhecido por Rambo, que foi posteriormente condenado a 46 anos de prisão. Essa sentença foi reformada posteriormente e a condenação passou a 15 anos e 4 meses ("Crime Ocorreu durante Blitz da Polícia Militar na Favela Naval", O Estado de S. Paulo, 16/4/2000).

6. Na ausência de tipificação do crime de tortura, os policiais acusados dessa prática eram processados com base no artigo $129, \S 6^{\circ}$ do Código Penal — lesão corporal grave, que previa penas muito inferiores àquelas cabíveis à gravidade do crime de tortura.

7. O positivismo jurídico representou uma tentativa de excluir todos os discursos que não estivessem relacionados com a lei escrita, a fim de manter a "pureza científica" do direito sem considerar fatores contingentes na construção do discurso sobre a lei (Goodrich, 1987).

8. A idéia de imparcialidade e neutralidade está intimamente associada ao princípio da igualdade, que estrutura o direito ocidental a partir da Revolução Francesa.

9. Um exemplo importante são as regras de registro da profissão, e da formação do sistema de obrigações profissionais que se manifesta na criação das Ordens de Advogados, que têm, por sua vez, um forte poder disciplinador da profissão (Karpik, 1996).

10. Ao discutir a hierarquia moral dos gêneros televisivos, Alasuutari (1992) analisou como o discurso sobre os programas é marcado por uma questão moral, de forma que as pessoas explicam o porquê de assistir a alguns gêneros ou não. Assim, alguns são avaliados como melhores ou piores em uma perspectiva comparativa entre os gêneros. Não se leva em conta o tipo ou o gênero, mas as convenções culturais 


\section{Vicente Riccio}

que estão por trás destes, como conceitos e tipologias que as pessoas utilizam em seus discursos sobre a televisão. Dessa forma, alguns modelos de programas são reconhecidos como merecedores de uma avaliação moral maior, ao passo que outros se situam em uma escala de mérito inferior. A hierarquia que surge da análise do discurso é a seguinte: " 1 - notícias e acontecimentos cotidianos; 2 - documentários sobre a natureza; 3 - comédias; 4 - esportes; 5 - séries de detetives; 6 - séries de ação; 7 -novelas". A hierarquia moral exposta pelos telespectadores independe da hierarquia de preferências individuais, em que há um quadro do "melhor ou do pior" em termos de gosto existente na sociedade. Como ilustra o estudo de Alasuutari, o tipo de programa popular situa-se em uma escala "menor" do gosto televisivo socialmente construído. Pode-se dizer que os reality shows se enquandram nesse grupo considerado "inferior" pelos telespectadores.

11. Na França, essa imprensa é representada pela revista Télérama, que tem um tratamento sofisticado sobre a televisão e sua programação.

\section{REFERÊNCIAS BIBLIOGRÁFICAS}

ALASUUTARI, Pertti. (1992), "I'm Ashamed to Admit but I Have Watched Dallas: The Moral Hierarchy of TV Programs". Media, Culture E Society, vol. 14, no 4, pp. 561-582.

. (1999), “Introduction: Three Phases of Reception Studies", in P. Alasuutari (org.), Rethinking the Media Audience. London, Sage.

ALMOND, Gabriel e VERBA, Sidney. (1965), The Civic Culture. Boston, Little \& Brown.

ARISTODEMU, Mary. (1993), "Studies in Law and Literature: Directions and Concerns". Anglo-American Law Review, vol. 22, pp. 157-193.

ARNAUD, André-Jean. (1998), "De la Globalisation au Post-Modernisme en Droit", in Entre Modernitéet Mondialisation: Cinq Leçons d'Histoire de la Philosophie du Droit et de l'État. Paris, LGDJ.

BRUSCHKE, Jon e LOGES, William E. (1999), “Relationship between Pretrial Publicity and Trial Outcomes". Journal of Communication, outono, pp. 104-120.

CHAMBAT, Pierre e EHRENBERG, Alain. (1993), “Les Reality Shows, Nouvel Âge Télévisuel?". Esprit, noำ188, pp. 5-12.

CHESTERMAN, Michael. (1997), “OJ and the Dingo: How Media Publicity Relating to Criminal Cases Tried by Jury is Dealt with in Australia and America". The American Journal of Comparative Law, vol. 45, pp. 109-147.

\section{2}

Revista Dados 


\section{A Lei em Tela e a Tela da Lei: O Direito e os Reality Shows}

COMMAILLE, Jacques. (2000), “De la Sociologie Juridique à une Sociologie Politique du Droit", in J. Commaille, L. Dumoulin e C. Robert (orgs.), La Juridicisation du Politique: Leçons Scientifiques. Paris, LGDJ.

COSTA, Maria Tereza P. (1992), O Programa Gil Gomes: A Justiça em Ondas Médias. Campinas, SP, Editora da Unicamp.

COTTERREL, Roger. (1997), “The Concept of Legal Culture”, in D. Nelken (org.), Comparing Legal Cultures. Aldershot, Darthmouth.

COWAN, Geoffrey. (1998), "The Legal and Ethical Limitations of Factual Misrepresentation". Annals of The American Academy of Political and Social Science, $\mathrm{n}$ 560, pp. 155-178.

DICTIONNAIRE Encyclopédique de Théorie et Sociologie du Droit. (1993), (organizado por André-Jean Arnaud). Paris, LGDJ.

ERICSON, Richard. (1996), “Why Law Is Like News”, in D. Nelken (org.), Law as Communication. Aldershot, Darthmouth.

EWICK, Patricia e SILBEY, Susan. (1998), The Common Place of Law: Stories from Everyday Life. Chicago/London, The University of Chicago Press.

FRIEDMAN, Lawrence M. (1985), Total Justice. s/l, s/e.

_. (1987) [1975], The Legal System: A Social Science Perspective. New York, Russel Sage Foundation.

__. (1994), “Is There a Modern Legal Culture?”. Ratio Juris, vol. 7, no 2, pp. 117-131.

GARAPON, Antoine. (1996a), Le Gardien des Promesses: Justice et Démocratie. Paris, Odile Jacob.

__. (1996b), La Republique Penalisée. Paris, Odile Jacob.

_. (1996c), "Justice Out of Court: The Dangers of Trial by Media", in D. Nelken (org.), Law as Communication. Aldershot, Darthmouth.

_ e SALAS, Denis. (1997), La Justice et le Mal. Paris, Odile Jacob.

GOODRICH, Peter. (1987), Legal Discourse. Studies in Linguistics, Rethoric and Legal Analysis. New York, St. Martin's Press.

HANNERZ, Ulf. (1992), La Complexité Culturelle. Manuscrito.

ISRAEL, Liora. (1999), "Les Mise en Scènes d'une Justice Quotidienne”. Droit et Société, no $42 / 43$, pp. 393-419.

KARPIK, Lucien. (1996), “Dispositifs de Confiance et Engagements Crédibles”. Sociologie du Travail, $\mathrm{n}$ - 4, pp. 527-550.

LASSITER, Christo. (1996), "TV or Not TV — That Is the Question”. The Journal of Criminal Law \& Criminology, vol. 86, no 3, pp. 903-1001.

LYNCH, Michael J., STRETESKY, Paul e HAMMOND, Paul. (2000), “Media Coverage of Chemical Crimes, Hillsborough County, Florida, 1987-97". British Journal of Criminology, vol. 40, pp. 112-126.

MARDER, Nancy. (1997), “Deliberations and Disclosures: A Study of Post-Verdict Interviews of Jurors". Iowa Law Review, vol. 82, pp. 467-541. 


\section{Vicente Riccio}

MEHL, Dominique. (1992), La Fenêtre et le Miroir: La Télévision et ses Programmes. Paris, Payot.

_. (1994), “La Télévision Compassionnelle”. Réseaux, no 63, pp. 102-121.

_. (1996), La Télévision de l'Intimité. Paris, Seuil.

NEWMAN, Paul. (1990), "Popular Culture and Criminal Justice: A Preliminary Analysis". Journal of Criminal Justice, vol. 18, pp. 261-274.

OST, François. (1996), "Jupiter, Hercules, Hèrmes: Trois Modelés du Juge", in P. Bouretz (org.), La Force du Droit. Paris, Esprit.

SALAS, Denis. (1998), "Le Tiers Pouvoir: Vers une Autre Justice". Paris, Hachette.

SANDERS, Joseph. (1987), “The Meaning of the Law Explosion: On Friedman's Total Justice". American-Bar Foundation Research Journal, no 2/3, pp. 601-615.

STEINER, Benjamin, BOWERS, William J. e SARAT, Austin. (1999), “Folk Knowledge as Legal Action: Death Penalty Judgments and the Tenet of Early Release in a Culture of Mistrust and Punitiveness". Law \& Society Review, vol. 33,no2, pp. 461-505.

THOMPSON, John B. (1998), A Mídia e a Modernidade. Petrópolis, RJ, Vozes.

TYLER, Tom. (1997), “Citizen Discontent with Legal Procedures: A Social Science Perspective on Civil Procedure Reform". The American Journal of Comparative Law, vol. 45 , pp. 871-904.

WERNECK VIANNA, Luiz, CARVALHO, Maria Alice Rezende de e MELO, Manuel Palácios da Cunha e. (1999), A Judicialização da Política e das Relações Sociais no Brasil. Rio de Janeiro, Revan. 
A Lei em Tela e a Tela da Lei: O Direito e os Reality Shows

ABSTRACT

Law on the Screen and the Screen of Law: Law and Reality Shows

This article aims to analyze the relationship between the law and the media in a context of judicialization of social relations. After analyzing the implications of this issue, the article affirms that a general theory of the media and law fails to properly explain the problem, since existing analyses are based on a relationship among individuals' attitudes towards official law. A better understanding of the topic requires an analysis of the type of program and the presence of concepts concerning fairness as differentiated from those expounded by operators of the law. The article concludes that this is the most appropriate way to verify popular concepts of justice appearing in a variety show.

Key words: law; media; common sense; reality shows

RÉSUMÉ

La Loi sur l'Écran et l'Écran de la Loi: Le Droit et les Reality Shows

Dans cet article, on cherche à analyser les rapports entre le droit et les média dans un contexte où les rapports sociaux se trouvent de plus en plus sous l'angle du juridique. Après une analyse des conséquences de ce fait, on soutient qu'une théorie générale à propos des média et du droit ne réussit pas à expliquer correctement le problème. Car les analyses, jusqu'à présent, s'en tiennent à une relation entre les attitudes des individus vis-à-vis du droit officiel. Pour mieux saisir le sujet, il faut tenir compte du genre de programme et de l'existence de conceptions sur ce qui est juste à la diffèrence de celles des gens du droit. On pense que c'est la façon la plus appropriée de reconnaître des conceptions populaires de justice dans une émission de variétés.

Mots-clé: droit; média; sens commun; reality shows 